\title{
Diagnosis of Overactive Bladder
}

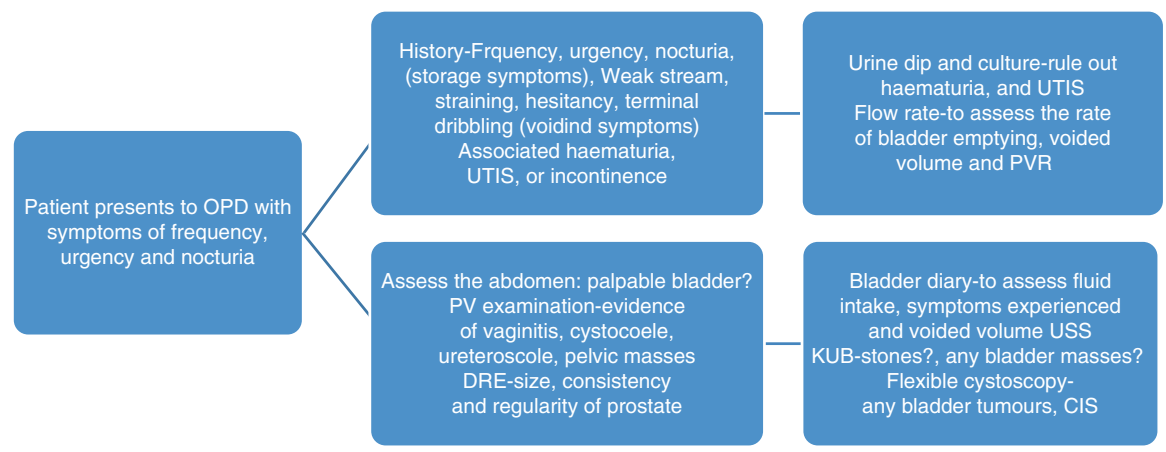

\section{Suggested Reading}

Corcos J, Przydacz M, Campeau L, Witten J, Hickling D, Honeine C, Radomski SB, Stothers L, Wagg A. CUA guideline on adult overactive bladder. Can Urol Assoc J. 2017;11(5):E142-73.

Gormley EA, Lightner DJ, Faraday M, Vasavada SP. Diagnosis and treatment of overactive bladder (non-neurogenic) in adults: AUA/SUFU guideline amendment. J Urol. 2015;193(5):1572-80.

Jayarajan J, Radomski SB. Pharmacotherapy of overactive bladder in adults: a review of efficacy, tolerability, and quality of life. Res Rep Urol. 2014;6:1-16.

Kim TH, Lee K-S. Persistence and compliance with medication management in the treatment of overactive bladder. Investig Clin Urol. 2016;57(2):84-93. 